\title{
Negative parental discipline, conduct problems and callous-unemotional traits: monozygotic twin differences study
}

\author{
Essi Viding, Nathalie M. G. Fontaine, Bonamy R. Oliver and Robert Plomin
}

\section{Background}

Negative parenting practices may be an environmental risk factor for subsequent conduct problems. Research on the association between parenting practices and callousunemotional traits, a risk factor for conduct problems, has produced mixed findings.

\section{Aims}

To investigate whether negative parental discipline is a nonshared environmental risk factor for the development of conduct problems and callous-unemotional traits.

\section{Method}

Longitudinal, multi-informant data from a community sample of twins were analysed using the monozygotic (MZ) twin differences design for 4508 twins (2254 twin pairs).

\section{Results}

Within MZ twin pairs, the twin receiving more negative parental discipline at 7 years had more conduct problems (but not more callous-unemotional traits) at 12 years.

\section{Conclusions}

During the transition to early adolescence, negative parental discipline operates as a non-shared environmental risk factor for development of conduct problems, but not for the development of callous-unemotional traits.

\section{Declaration of interest}

None.
Negative parental discipline is associated with increased risk of conduct problems. ${ }^{1}$ Children who grow up in the same family can face markedly different parental discipline ${ }^{2}$ and previous data using the monozygotic (MZ) twin differences design confirm that differences in negative parental discipline are a non-shared environmental risk factor associated with differences in the level of concurrent conduct problems. ${ }^{3}$ Longitudinal MZ twin differences data also suggest that maternal negative emotional attitudes towards children at age 5 may be a causal environmental factor for the development of subsequent conduct problems at age $7 .^{4}$

To our knowledge, no research to date has used the MZ twin differences design to assess whether differences in negative parental discipline represent a possible causal environmental factor for the development of conduct problems. Moreover, no MZ twin differences studies have been conducted to assess whether negative parental discipline is a non-shared environmental factor contributing to the development of callous-unemotional traits. Callous-unemotional traits are a well-documented temperamental correlate of severe and persistent antisocial behaviour. ${ }^{5}$ Callousunemotional traits show moderate to strong heritability, as well as non-shared environmental effects. ${ }^{6,7}$ The heritable influences on callous-unemotional traits are substantially shared with conduct problems, but there is only a modest overlap in the non-shared environmental influences for callous-unemotional traits and conduct problems. ${ }^{8}$ Several findings have suggested that children with callous-unemotional traits may react less to negative parental practices than their peers with conduct problems, ${ }^{9-12}$ although other findings indicate that parenting may have some impact on the level of callous-unemotional traits in community samples. ${ }^{13,14}$ Taken together, previous findings encourage the investigation of negative parental discipline as a potential nonshared environmental factor contributing to individual differences in callous-unemotional traits. The primary aim of the current study was to use the MZ twin differences design to examine the environmental effects of negative parental discipline on the parent- and teacher-rated conduct problems and callousunemotional traits from childhood to early adolescence (7-12 years).

\section{Method}

\section{Sample}

Participants were drawn from the Twins Early Development Study (TEDS), a longitudinal study of twin pairs ascertained from population records of twin births in England and Wales between 1994 and 1996. The TEDS has been shown to be reasonably representative of the UK population, and is described in detail elsewhere. ${ }^{15,16}$ The sample for the phenotypic analyses consisted of $4508 \mathrm{MZ}$ twins (46.0\% males), born in 1994, 1995 and 1996, who had data available from parents' or teachers' ratings (or both) of behavioural problems at 12 years of age (outcome measures). Mothers provided $98.4 \%$ of the ratings at age 7 . The source of parental data was not collected at age 12, but the percentage of maternal ratings was estimated to be similar to the age 7 data collection by the TEDS coordinator (P. Busfield, personal communication, 2009). The MZ twin differences analyses were thus conducted on 2254 twin pairs. A total of 490 twins were excluded from the analyses because of missing data at 12 years old. Based on the assessment at 7 years, there was no statistical difference between the participants in the final sample and those who were not included on negative parental discipline (mean 0.02 v. $0.10, P>0.05)$ and teacher-rated callous-unemotional traits (mean 3.53 v. 3.91, $P>0.05$ ). However, participants in the final sample compared with those excluded had lower levels of teacher-rated conduct problems at 7 years old (mean $0.67 v$. $0.93, P<0.05)$. Monozygotic twins with severe medical or neurological problems were also excluded from the analyses. ${ }^{17}$ Zygosity was assigned using DNA testing in $76.6 \%$ of the cases. 
For those twins who did not provide DNA samples, parental ratings of physical similarity were used to determine the zygosity. This method assigns zygosity with more than 95\% accuracy as validated by genotyping. ${ }^{18}$

\section{Measures}

The descriptive statistics of all measures are presented in Table 1.

\section{Negative parental discipline}

Negative parental discipline was assessed using questionnaire items adapted from a semi-structured interview ${ }^{19}$ at age 7. Parents reported on their use of the following negative discipline strategies with the child: restraining or smacking; sending the child to their room or withdrawing privileges; raising voice or shouting; and ignoring the child when they are misbehaving. The four items were rated on a 4-point scale (from never to often) for the firstborn twin, followed by ratings on a 3-point scale (less, same or more) for the second-born twin. This rating method was chosen in order to focus parents on potential differences in their treatment of the two children. For first-born twins, the sum of the respective items was standardised for the whole population to zero mean and unit variance. For second-born twins, this standardised sum was added to the standardised sum of the differential items indicating more or less parental feeling; this composite score was then standardised. ${ }^{20}$ Cronbach's alpha for the negative parental discipline was computed separately for the first- and second-born twins because the rating method was not identical for both. Cronbach's alpha was 0.56 for the first-born twins and 0.65 for the second-born twins.

\section{Conduct problems}

Conduct problems at 7 and 12 years were assessed using the Strengths and Difficulties Questionnaire (SDQ), ${ }^{21}$ a five-item scale including items such as 'Often fights with other children or bullies them' and 'Often lies or cheats'. Each item was rated on a 3-point scale as certainly true, somewhat true, or not true. The SDQ is a widely used screening instrument in the UK and its reliability and validity have been demonstrated using a large, national sample. ${ }^{22}$ Three of the conduct problem items reflected aggressive or bad temper tendencies, whereas the remaining two assessed lying and stealing. Cronbach's alphas were 0.58 and 0.60 for the

\begin{tabular}{|c|c|c|c|c|}
\hline Variable & Mean & s.d. & Skewness & Kurtosis \\
\hline \multicolumn{5}{|l|}{ Parents' ratings } \\
\hline Age 7 & 1.62 & 2.08 & 1.18 & 1.88 \\
\hline Age 12 & 1.31 & 1.95 & 1.30 & 2.32 \\
\hline \multicolumn{5}{|l|}{ Teachers' ratings } \\
\hline Age 7 & 0.69 & 1.95 & 2.60 & 8.14 \\
\hline Age 12 & 0.59 & 1.81 & 2.83 & 9.65 \\
\hline \multirow{2}{*}{\multicolumn{5}{|c|}{$\begin{array}{l}\text { Callous-unemotional traits } \\
\text { Parents' ratings }\end{array}$}} \\
\hline & & & & \\
\hline Age 7 & 3.00 & 2.55 & 0.57 & 0.16 \\
\hline Age 12 & 2.81 & 2.69 & 0.63 & 0.23 \\
\hline \multicolumn{5}{|l|}{ Teachers' ratings } \\
\hline Age 7 & 3.54 & 3.83 & 0.60 & 0.04 \\
\hline Age 12 & 3.08 & 3.42 & 0.75 & 0.24 \\
\hline \multicolumn{5}{|l|}{ Negative parental discipline ${ }^{a}$} \\
\hline Parents' ratings, age 7 & 0.02 & 1.34 & 0.09 & -0.15 \\
\hline $\begin{array}{l}\text { a. The negative parental discip } \\
\text { may have affected the mean a } \\
\text { (see Method for more details). }\end{array}$ & $\begin{array}{l}\text { varia } \\
\text { the st }\end{array}$ & $\begin{array}{l}\text { stan } \\
\text { devia }\end{array}$ & $\begin{array}{l}\text { sed. The sam } \\
\text { cores prese }\end{array}$ & $\begin{array}{l}\text { selection } \\
\text { here }\end{array}$ \\
\hline
\end{tabular}

parents' ratings at ages 7 and 12 respectively, and 0.71 and 0.67 for the teachers' ratings at ages 7 and 12 respectively. The cross-informant (parent-teacher) cross-sectional and longitudinal correlations for conduct problems ranged from 0.24 to 0.32 (Table 2 ). The within-informant longitudinal correlations ranged from 0.36 to 0.51 (Table 2 ).

\section{Callous-unemotional traits}

Callous-unemotional traits at 7 and 12 years were assessed using seven items available in TEDS: three Antisocial Process Screening Device $^{23}$ items, and four items from the SDQ. These items were either original callous-unemotional trait items ('Does not show feelings or emotions', 'Feels bad or guilty if he/she does something wrong' (reverse scored), 'Is concerned about how well he/she does at school' (reverse scored)) or were selected to reflect callous-unemotional traits (e.g. 'Considerate of other people's feelings' (reverse scored)) (see Viding et al). ${ }^{6}$ None of the items overlapped with any of the conduct problem items. Cronbach's alphas were 0.46 and 0.54 for the parents' ratings at ages 7 and 12 respectively, and 0.74 and 0.71 for the teachers' ratings at ages 7 and 12 respectively. The cross-informant (parent-teacher) crosssectional and longitudinal correlations for callous-unemotional traits ranged from 0.12 to 0.23 (Table 2). The within-informant longitudinal correlations ranged from 0.27 to 0.32 (Table 2).

\section{Testing procedures}

Informed, written consent was obtained from all of the families who agreed to take part in the study. The families were told that TEDS encompasses assessment of cognitive ability, behavioural problems and prosocial behaviours, and that all of the data would be anonymised and published in a way that did not identify any individual child. Teachers were approached only if there was family consent for teacher involvement. The study and the consent procedure were approved by the Institute of Psychiatry and Maudsley ethics committee.

\section{Data analyses}

The analyses proceeded in three steps. The first step was the phenotypic analysis; that is, we tested whether negative parental discipline was associated with children's conduct problems and

Table 2 Correlations between parents' and teachers' reports of children's conduct problems and callous-unemotional traits at 7 and 12 years old ${ }^{a}$

\begin{tabular}{|c|c|c|c|c|}
\hline & \multicolumn{4}{|c|}{ Rating } \\
\hline & 1 & 2 & 3 & 4 \\
\hline \multicolumn{5}{|l|}{ Conduct problems } \\
\hline \multicolumn{5}{|l|}{ Age 7} \\
\hline 1. Parents' ratings & - & $0.32^{b}$ & $0.51^{\mathrm{c}}$ & $0.24^{d}$ \\
\hline 2. Teachers' ratings & & - & $0.24^{d}$ & $0.36^{\mathrm{c}}$ \\
\hline \multicolumn{5}{|l|}{ Age 12} \\
\hline 3. Parents' ratings & & & - & $0.27^{\mathrm{b}}$ \\
\hline 4. Teachers' ratings & & & & - \\
\hline \multicolumn{5}{|c|}{ Callous-unemotional traits } \\
\hline \multicolumn{5}{|c|}{ Age 7} \\
\hline 1. Parents' ratings & - & $0.23^{\mathrm{b}}$ & $0.32^{c}$ & $0.12^{d}$ \\
\hline 2. Teachers' ratings & & - & $0.18^{d}$ & $0.27^{\mathrm{C}}$ \\
\hline \multicolumn{5}{|l|}{ Age 12} \\
\hline 3. Parents' ratings & & & - & $0.17^{\mathrm{b}}$ \\
\hline 4. Teachers' ratings & & & & - \\
\hline \multicolumn{5}{|c|}{$\begin{array}{l}\text { a. All correlations are significant at } P \leqslant 0.001 \text {. Depending on the analysis, } n=4126-4507 \text {. } \\
\text { b. Cross-source (cross-sectional) correlations. } \\
\text { c. Longitudinal (within-source) correlations. } \\
\text { d. Longitudinal (cross-source) correlations. }\end{array}$} \\
\hline
\end{tabular}


callous-unemotional traits. We used the COMPLEX analysis option in Mplus, Version 4.2 for Windows (www.statmodel.com) to account for the non-independence of observations (i.e. twins). ${ }^{24}$ Second, we examined the MZ twin correlations to ascertain whether there were differences within MZ twin pairs in the negative parental discipline and behavioural problems. Third, we tested if differences between MZ twin pairs in negative parental discipline were associated with differences between MZ twin pairs in their conduct problems and callous-unemotional traits. This MZ twin differences design provides a strong test of the specific unique environmental experiences that make family members different from each other (termed non-shared environmental influences) independently of genetics, because MZ twins share $100 \%$ of their genes. ${ }^{25}$ This method permits the examination of unique environmental influences on behaviour, free of passive or evocative gene-environment correlations that have been shown to influence parenting-behaviour relationships. ${ }^{26}$ Passive geneenvironment correlation refers to the phenomenon where the child's behaviour and the environment provided by the parent are correlated because both share a genetically transmitted liability. Evocative gene-environment correlation refers to a phenomenon where the child's genetically influenced behaviour evokes different parental treatment.

Missing data were managed through Full Information Maximum Likelihood using Mplus, Version 4.2 on Windows. ${ }^{24}$ As expected in a population sample, the conduct problem scales (parents' and teachers' ratings) were skewed to the 'no problem' end (Table 1). To correct for skew, we applied a logarithmic transformation. However, the pattern of results remained after the transformation, so we report the findings using the untransformed scales. We conducted both phenotypic and MZ twin differences analyses separately for parents' and teachers' reports, and separately for conduct problems and callous-unemotional traits (first and third step of the analyses, see above). We examined:

(a) cross-sectional associations (e.g. the association between negative parental discipline at age 7 and conduct problems at age 7 );

(b) longitudinal associations (e.g. the association between negative parental discipline at age 7 and conduct problems at age 12);

(c) longitudinal associations controlling for age 7 measures (e.g. the association between negative parental discipline at age 7 and conduct problems at age 12, controlling for conduct problems at age 7).

Participants with Mahalanobis distance scores at $P<0.001$ (outlier cases) were excluded from the regression analyses that examined the behavioural problems at age 12 controlling for age 7 measures.

\section{Results}

Prior to conducting the MZ twin differences analyses, two conditions had to be satisfied. First, a phenotypic relationship had to be demonstrated between negative parental discipline and conduct problems, as well as negative parental discipline and callous-unemotional traits. Second, it was important to ascertain that the MZ twins, although genetically identical and growing up in the same family, differed for conduct problems, callous-unemotional traits and negative parental discipline (to allow for the possibility of MZ twin differences in parenting contributing to $\mathrm{MZ}$ twin differences in conduct problems and callous-unemotional traits). After these checks, it was possible to test whether MZ twin differences in negative parental discipline were associated with differences between MZ twins in conduct problems and callous-unemotional traits.

\section{Is negative parental discipline associated with parent- and teacher-rated conduct problems and/or callous-unemotional traits?}

The correlations between negative parental discipline and parentand teacher-rated conduct problems and callous-unemotional traits were modest to moderate $(0.11-0.43)$, but statistically significant both cross-sectionally (at 7 years) and longitudinally (from 7 to 12 years), as shown in Table 3. Table 3 also shows the results of longitudinal regression analyses predicting intraindividual changes in conduct problems and callous-unemotional traits from ages 7 to 12 as a function of negative parental discipline at age 7. For analysis of conduct problems, the children's conduct problem score at 7 was entered, followed by negative parental discipline when the children were 7 years old. A longitudinal effect of negative parental discipline at age 7 on conduct problems at age 12 (over and above any continuity of conduct problems from ages 7 to 12) was indicated for both parents' and teachers' ratings of conduct problems. The same analysis was repeated for callous-unemotional traits. Slightly weaker findings were observed for callous-unemotional traits compared with conduct problems (Table 3). The documentation of statistically significant phenotypic relationships between negative parental discipline and conduct problems/callous-unemotional traits satisfied the first condition for proceeding with the MZ twin differences analyses for both conduct problems and callous-unemotional traits.

\section{Are there differences between $\mathrm{MZ}$ twins on conduct problems, callous-unemotional traits and negative parental treatment?}

Table 4 lists the intra-pair MZ correlations indexing similarity between MZ twins in their conduct problems, callous-unemotional traits and negative parental discipline. Although genetically

Table 3 Cross-sectional and longitudinal associations between negative parental discipline (at age 7) and children's conduct problems and callous-unemotional (at ages 7 and 12), according to parents' and teachers' ratings of conduct problems and callous-unemotional traits ${ }^{a}$

\begin{tabular}{|c|c|c|c|c|c|c|}
\hline & \multicolumn{3}{|c|}{ Parents' ratings } & \multicolumn{3}{|c|}{ 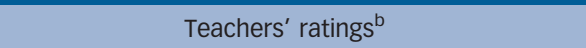 } \\
\hline & $\begin{array}{l}\text { At age } 7, \\
\text { cross- } \\
\text { sectional } r\end{array}$ & $\begin{array}{l}\text { At age } 12 \text {, } \\
\text { Iongitudinal } r\end{array}$ & $\begin{array}{l}\text { At age } 12 \text {, controlling } \\
\text { for age } 7 \text { behaviour } \\
\text { problems, } b\end{array}$ & $\begin{array}{l}\text { At age } 7, \\
\text { cross- } \\
\text { sectional } r\end{array}$ & $\begin{array}{l}\text { At age } 12, \\
\text { longitudinal } r\end{array}$ & $\begin{array}{l}\text { At age } 12, \text { controlling } \\
\text { for age } 7 \text { behaviour } \\
\text { problems, } b\end{array}$ \\
\hline \multicolumn{7}{|l|}{ Conduct problems } \\
\hline Negative parental discipline & 0.43 & 0.33 & 0.13 & 0.20 & 0.16 & 0.10 \\
\hline \multicolumn{7}{|l|}{ Callous-unemotional traits } \\
\hline Negative parental discipline & 0.15 & 0.13 & 0.09 & 0.16 & 0.11 & 0.07 \\
\hline $\begin{array}{l}r \text {, correlations; } b \text {, standardised regre } \\
\text { a. All } P \leqslant 0.001 \text {. Depending on the ar } \\
\text { b. Different teachers rated the child }\end{array}$ & $\begin{array}{l}4465 . \\
12 .\end{array}$ & & & & & \\
\hline
\end{tabular}




\begin{tabular}{|c|c|}
\hline Variable & $r$ \\
\hline \multicolumn{2}{|l|}{ Conduct problems } \\
\hline \multicolumn{2}{|l|}{ Parents' ratings } \\
\hline Age 7 & 0.73 \\
\hline Age 12 & 0.77 \\
\hline \multicolumn{2}{|l|}{ Teachers' ratings } \\
\hline Age 7 & 0.69 \\
\hline Age 12 & 0.60 \\
\hline \multicolumn{2}{|l|}{ Callous-unemotional traits } \\
\hline \multicolumn{2}{|l|}{ Parents' ratings } \\
\hline Age 7 & 0.63 \\
\hline Age 12 & 0.81 \\
\hline \multicolumn{2}{|l|}{ Teachers' ratings } \\
\hline Age 7 & 0.71 \\
\hline Age 12 & 0.56 \\
\hline \multicolumn{2}{|l|}{ Negative parental discipline } \\
\hline Parents' ratings, age 7 & 0.76 \\
\hline
\end{tabular}

identical and growing up in the same family, the MZ twins were not identical on any of the measures at either age. For instance, approximately $25-40 \%$ of the variance in children's conduct problems could be attributed to non-shared environmental factors (plus measurement error): parents' ratings at 7 years: 1 $0.73=0.27$; parents' ratings at age $12: 1-0.77=0.23$; teachers' ratings at 7 years $1-0.69=0.31$; teachers' ratings at age 12 years: $1-0.60=0.40)$. Similar findings were observed for callousunemotional traits (Table 4). This demonstration of non-shared environmental effects satisfied the second condition for proceeding with the MZ twin differences analyses.

\section{Are $M Z$ twin differences in negative parental discipline related to MZ twin differences in conduct problems and callous-unemotional traits?}

Table 5 shows the correlations between MZ twin differences in negative parental discipline and $\mathrm{MZ}$ twin differences in parentand teacher-rated conduct problems and callous-unemotional traits. The correlations between MZ twin differences in negative parental discipline and parent- and teacher-rated conduct problems were modest, but statistically significant both crosssectionally (at 7 years old) and longitudinally (from 7 to 12 years old) (Table 5). A longitudinal effect of negative parental discipline at age 7 on conduct problems at age 12 (over and above continuity of conduct problems from ages 7 to 12) was documented for both parents' and teachers' ratings of conduct problems. On the other hand, MZ twin differences in negative parental discipline at age 7 were significantly correlated with MZ twin differences in callousunemotional traits, cross-sectionally for parents' and teachers' ratings, but only for parent-rated callous-unemotional traits when examining the data longitudinally. Regression analyses predicting callous-unemotional traits at age 12 controlling for age 7 callous-unemotional traits did not show a longitudinal effect of negative parental discipline at age 7 for either parents' or teachers' ratings of callous-unemotional traits.

\section{Discussion}

The primary aim of our study was to investigate the crosssectional and longitudinal relationships between parent-reported negative parental discipline and parent- and teacher-rated conduct problems and callous-unemotional traits from childhood to early adolescence (7-12 years). To our knowledge this was the first study to investigate the longitudinal effects of negative parental discipline on conduct problems using the MZ twin differences design, although a previous MZ twin differences study has documented a significant environmental effect of maternal negative emotional attitudes on conduct problems in a younger age group. ${ }^{4}$ Moreover, the current study was the first to explore negative parental discipline as a non-shared environmental candidate for callous-unemotional traits. The strengths of the study include longitudinal, multi-informant data spanning a 5 -year period, as well as the genetically informative MZ twin differences design.

\section{Negative parental discipline as an environmental risk factor for conduct problems}

We found a longitudinal association between negative parental discipline and conduct problems. Specifically, the member of the MZ twin pair who had received more parent-reported negative parental discipline at age 7 was more likely to have higher levels of conduct problems at age 12 than the co-twin. This finding held even after the initial MZ twin differences in conduct problems at age 7 were controlled for in the analyses. Importantly, this finding was robust both within (parent-rated conduct problems) and across informants (teacher-rated conduct problems). Although previous phenotypic research has demonstrated an association between negative parental discipline and subsequent conduct problems, no previous studies have explored the role of negative parental discipline as a specific non-shared environmental

Table 5 Cross-sectional and longitudinal associations between monozygotic (MZ) twin differences in negative parental discipline (at age 7) and children's conduct problems and callous-unemotional traits (at ages 7 and 12), according to parents' and teachers' ratings of conduct problems and callous-unemotional traits ${ }^{a}$

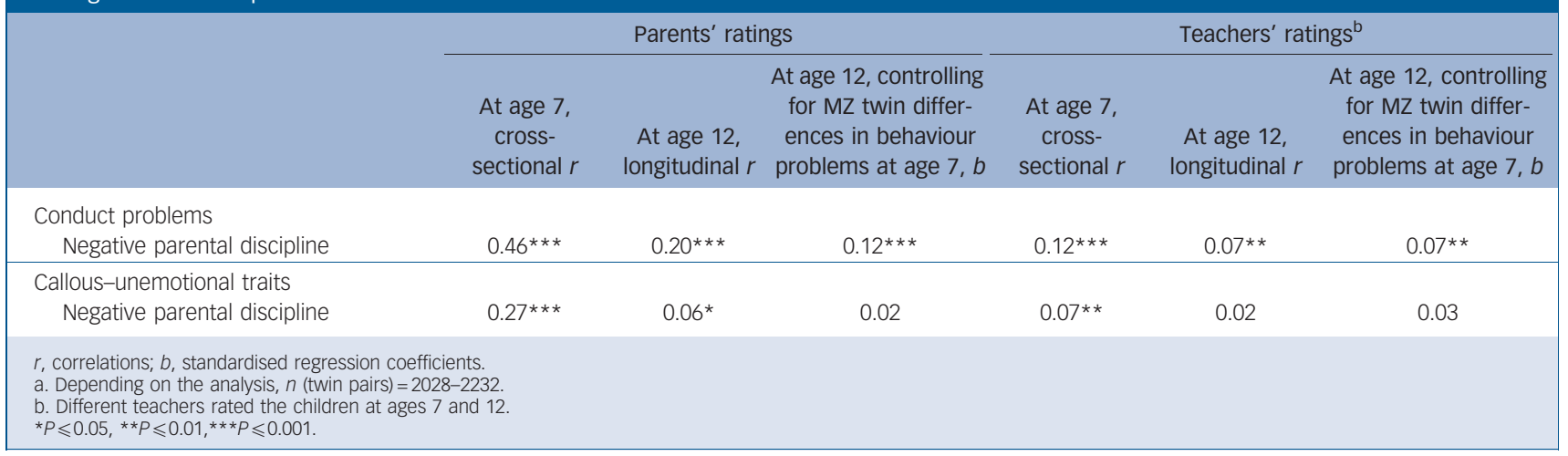


candidate for conduct problems using a longitudinal MZ twin differences design. Indeed, only one previous study has used the longitudinal MZ twin differences design to examine the association between negative maternal feelings and conduct problems; ${ }^{4}$ this study showed that differences in negative maternal feelings at age 5 predicted subsequent differences in conduct problems during early school years (at age 7).

\section{Negative parental discipline and conduct problems in early adolescence}

Our study focused on children's outcomes during the period of entry to adolescence, for which there are no previous longitudinal MZ twin differences data. This period is critical since it covers a time when children may be starting delinquent careers. The current study suggests that negative parental discipline may be one specific non-shared environmental risk factor that contributes to conduct problems in early adolescence.

\section{The strength of the $M Z$ differences design in documenting a non-shared environmental effect}

The MZ twin differences design ensures that pure non-shared environmental effects, rather than gene-environment interaction or evocative gene-environment correlation, are quantified. Because the members of the MZ twin pair are genetically identical to each other, any environmental effects operate upon genotype effects that do not differ between the members of the MZ twin pair. Of course we cannot rule out that some unmeasured, early non-genetic influences between the MZ twins could have contributed to our findings. To minimise this confound, all twins with documented medical, neurological and physical health diagnoses, as well as those with birth complications or low birth-weight, were excluded from our analyses.

\section{Negative parental discipline and callous-unemotional traits}

Several studies have reported that non-shared environmental influences are important in explaining the variance in callousunemotional traits (see for example Viding et al), ${ }^{8}$ yet we found no longitudinal environmental effect of differential negative parental discipline for differences in subsequent callous-unemotional traits. Although it is conceptually plausible that moderate internal consistency of the measures could have been responsible for the difficulty in uncovering a true relationship between differential parenting and callous-unemotional traits, this explanation is unlikely. The internal consistencies for callous-unemotional traits and conduct problems were very similar for both parent and teacher ratings; in fact, teacher-rated callous-unemotional traits showed higher internal consistency than teacher-rated conduct problems. Therefore the different pattern of findings with regard to callous-unemotional traits and conduct problems is likely to reflect a true difference between these two domains in whether negative parental discipline represents a non-shared environmental risk factor for subsequent outcome. The lack of an environmental contribution of negative parental discipline and subsequent callous-unemotional traits is somewhat surprising as phenotypic analyses in both this and other studies have demonstrated a longitudinal relationship between parenting variables and level of callous-unemotional traits. ${ }^{13,14}$ It is possible that the relationship between parental practices and level of callous-unemotional traits demonstrated in the phenotypic analysis reflects passive and/or evocative gene-environment correlation, which would not be found with the MZ twin differences analysis that focuses on non-shared environment. In other words, the phenotypic relationship is likely to reflect a true association, but one that does not operate through non-shared environmental influence of negative parental practices.

\section{Negative parental discipline is not a uniform non- shared environmental risk factor for both conduct problems and callous-unemotional traits}

Analyses investigating the aetiology of conduct problems and callous-unemotional traits suggest that although non-shared environmental influences are important for both conduct problems and callous-unemotional traits, there is only a modest overlap for these influences between the two domains. ${ }^{8}$ The data from the current analyses are thus in line with the notion that much of the non-shared environmental influences important for conduct problems need not be shared with callous-unemotional traits. The newly expanding literature on callous-unemotional traits in childhood is pointing to such traits as indicative of poor long-term outcomes, particularly for adult psychopathy and criminality. ${ }^{5}$ Moreover, studies have indicated substantial genetic influence on these traits ${ }^{6,7}$ and there are data suggesting that these children may be less responsive to some parenting intervention programmes than children with conduct problems alone. ${ }^{27}$ Alongside such findings, the current study serves to emphasise a considerable challenge remaining for researchers and clinicians alike; that is, to identify and subsequently target environmental, including parenting, factors that may be addressed in order to ameliorate callous-unemotional traits.

\section{Study limitations}

Our study is not without its limitations. On the face of it, differences in the negative parental discipline at age 7 accounted for a disappointingly small amount of differences in parent- and teacher-rated conduct problems at age 12 over and above conduct problems at age $7(0.5-1.4 \%$ of the variance accounted for). However, such effect sizes are common for the studies utilising the MZ twin differences design, and are likely to reflect the fact that unlike phenotypic analyses of the effects of supposed 'environmental' variables on variance in children's outcomes, the $\mathrm{MZ}$ twin differences design does not include genetically mediated associations between the environment and children's behaviour. $^{3,28,29}$ It is becoming increasingly clear through studies like ours that the variance in children's behaviour is accounted for by numerous different aspects of the environment, as well as many diverse genetic factors.

A further limitation concerns the internal consistency of the measures of negative parental discipline, conduct problems and callous-unemotional traits, which was only moderate in some cases (Cronbrach's alphas ranging between 0.46 and 0.74 ). This could have produced more conservative estimates of the magnitude of association between the measures of conduct problems and callous-unemotional traits and the measure of negative parental discipline. Moreover, we cannot rule out that non-systematic measurement error stemming from the moderate reliability of our measures did not inflate the difference scores for identical twins. However, this is unlikely to account for the systematic pattern of our findings that demonstrate a non-shared environmental effect on conduct problems, but not on callousunemotional traits, across raters.

Another limitation that critics of the twin method often highlight is that there may be important twin-singleton differences that would jeopardise the conclusions from the twin studies, such as our current investigation. Although twins are delayed in language development and twin pregnancies are associated with 
increased rate of obstetric complications, neither concern is particularly relevant for twin data on conduct problems and callous-unemotional traits. Twins with obstetric complications were excluded from our analyses and language delay found in twins is very mild, representing variation in the normal range. ${ }^{30}$

\section{Implications of the current findings}

Negative parental discipline represents a non-shared environmental risk factor for development of further conduct problems during the transition to early adolescence. However, negative parental discipline does not appear to represent a non-shared environmental risk factor for callous-unemotional traits during this period. Previous research suggests that the non-shared environmental influences for conduct problems and callous-unemotional traits are largely independent ${ }^{8}$ and findings from this study highlight negative parental discipline as a possible causal risk factor for the development of conduct problems, but not callous-unemotional traits. The phenotypic relationship that is observed between negative parental practices and level of callous-unemotional traits may reflect genetic endowment (both provided by the parent as well as evoked by the child's temperament) within families who have a child with callous-unemotional traits.

Essi Viding, PhD, Division of Psychology and Language Sciences, University College London and Institute of Psychiatry, King's College London, UK; Nathalie M. G. Fontaine, PhD, Division of Psychology and Language Sciences, University Colleg London, UK, and Department of Criminal Justice, Indiana University, Indiana, USA; Bonamy R. Oliver, PhD, Robert Plomin, PhD, Institute of Psychiatry, King's College London, UK

Correspondence: Essi Viding, PhD, Division of Psychology and Language Sciences, University College London, 26 Bedford Way, London WC1H OAP, UK. Email: e.viding@ucl.ac.uk

First received 31 Oct 2008, final revision 12 Jun 2009, accepted 8 Jul 2009

\section{Funding}

Twins Early Development Study receives support from the UK Medical Research Counci (G0500079).

\section{Acknowledgements}

The authors are indebted to the twins, their parents and teachers.

\section{References}

1 Hill J. Biological, psychological and social processes in the conduct disorders. J Child Psychol Psychiatry 2002; 43: 133-64.

2 Plomin R. Genetics and Experience. Sage, 1994.

3 Asbury K, Dunn JF, Pike A, Plomin, R. Nonshared environmental influences on individual differences in early behavioral development: a monozygotic twin differences study. Child Dev 2003; 74: 933-43.

4 Caspi A, Moffitt TE, Morgan J, Rutter M, Taylor A, Arseneault L, et al. Maternal expressed emotion predicts children's antisocial behavior problems: using monozygotic-twin differences to identify environmental effects on behavioral development. Dev Psychol 2004; 40: 149-61.

5 Frick PJ, White SF. Research review: the importance of callous-unemotional traits for developmental models of aggressive and antisocial behavior. J Child Psychol Psychiatry 2008; 49: 359-75.

6 Viding E, Blair RJ, Moffitt TE, Plomin R. Evidence for substantial genetic risk for psychopathy in 7-year-olds. J Child Psychol Psychiatr 2005; 46: 592-7.
7 Viding E, Jones AP. Cognition to genes via the brain in the study of conduct disorder. Q J Exp Psychol 2008; 61: 171-81.

8 Viding E, Frick PJ, Plomin R. Aetiology of the relationship between callousunemotional traits and conduct problems in childhood. Br J Psychiatry 2007; 190 (suppl 49): s33-8.

9 Wootton JM, Frick PJ, Shelton KK, Silverthorn P. Ineffective parenting and childhood conduct problems: the moderating role of callous-unemotional traits. J Consult Clin Psychol 1997; 65: 301-8.

10 Oxford M, Cavell TA, Hughes JN. Callous/unemotional traits moderate the relation between ineffective parenting and child externalizing problems: a partial replication and extension. J Clin Child Adolesc Psychol 2003; 32: 577-85.

11 Hipwell AE, Pardini DA, Loeber R, Sembower M, Keenan K, StouthamerLoeber M. Callous-unemotional behaviors in young girls: shared and unique effects relative to conduct problems. J Clin Child Adolesc Psychol 2007; 36: 293-304.

12 Lynam DR, Loeber R, Stouthamer-Loeber M. The stability of psychopathy from adolescence into adulthoold. Crim Justice Beh 2008; 35: 228-43.

13 Frick PJ, Kimonis ER, Dandreaux DM, Farell JM. The 4 year stability of psychopathic traits in non-referred youth. Behav Sci Law 2003; 21: 713-36.

14 Pardini DA, Lochman JE, Powell N. The development of callous-unemotional traits and antisocial behavior in children: are there shared and/or unique predictors? J Clin Child Adolesc Psychol 2007; 36: 319-33.

15 Trouton A, Spinath FM, Plomin R. Twins early development study (TEDS): a multivariate, longitudinal genetic investigation of language, cognition and behavior problems in childhood. Twin Res 2002; 5: 444-8.

16 Oliver BR, Plomin R. Twins Early Development Study (TEDS): a multivariate, longitudinal genetic investigation of language, cognition and behavior problems from childhood through adolescence. Twin Res Hum Genet 2007; 10: 96-105.

17 Kovas Y, Haworth CM, Dale PS, Plomin R. The genetic and environmental origins of learning abilities and disabilities in the early school years. Monogr Soc Res Child Dev 2007; 72: vii, 1-144.

18 Price TS, Freeman B, Craig I, Petrill SA, Ebersole L, Plomin R. Infant zygosity can be assigned by parental report questionnaire data. Twin Res 2000; 3: 129-33.

19 Deater-Deckard K, Dodge KA., Bates JE, Pettit GS. Multiple risk factors in the development of externalising behavior problems: group and individual differences. Dev Psychopathol 1998; 10: 469-93.

20 Knafo A, Plomin R. Parental discipline and affection and children's prosocial behavior: genetic and environmental links. J Pers Soc Psychol 2006; 90 : 147-64.

21 Goodman R. The Strengths and Difficulties Questionnaire: a research note J Child Psychol Psychiatry 1997; 38: 581-6.

22 Goodman R. Psychometric properties of the strengths and difficulties questionnaire. J Am Acad Child Adolesc Psychiatry 2001; 40: 1337-45.

23 Frick PJ, Hare RD. Antisocial Process Screening Device. Multi-Health Systems, 2001.

24 Muthén LK, Muthén BO. Mplus Statistical Analysis with Latent Variables: User's Guide, (4th edn). Muthén \& Muthén, 1998-2007.

25 Pike A, Reiss D, Hetherington EM, Plomin R. Using MZ differences in the search for nonshared environmental effects. J Child Psychol Psychiatry 1996; 37: 695-704.

26 Moffitt TE. The new look of behavioral genetics in developmental psychopathology: gene-environment interplay in antisocial behaviors. Psychol Bull 2005; 131: 533-54.

27 Hawes DJ, Dadds MR. The treatment of conduct problems in children with callous-unemotional traits. J Consult Clin Psychol 2005; 73: 737-41.

28 Oliver BR, Pike A, Plomin R. Nonshared environmental influences on teacherreported behaviour problems: monozygotic twin differences in perceptions of the classroom. J Child Psychol Psychiatry 2008; 49: 646-53.

29 Turkheimer E, Waldron M. Nonshared environment: a theoretical, methodological, and quantitative review. Psychol Bull 2000; 126: 78-108.

30 Rutter M. Genes and Behavior: Nature-Nurture Interplay Explained. Blackwell Publishing, 2006. 